\title{
Dam break flood wave under different reservoir's capacities and lengths
}

\author{
FARHAD HOOSHYARIPOR ${ }^{1,2}$, AHMAD TAHERSHAMSI $^{2, *}$ and SAHAND RAZI ${ }^{3}$ \\ ${ }^{1}$ Department of Civil Engineering, Science and Research Branch, Islamic Azad University, Tehran, Iran \\ ${ }^{2}$ Faculty of Civil and Environment Engineering, Amirkabir University of Technology, Tehran, Iran \\ ${ }^{3}$ Department of Civil Engineering, Islamshar Branch, Islamic Azad University, Islamshahr, Iran \\ e-mail: tshamsi@aut.ac.ir
}

MS received 17 May 2016; revised 15 January 2017; accepted 29 January 2017; published 14 July 2017

\begin{abstract}
Dam failure has been the subject of many hydraulic engineering studies due to its complicated physics with many uncertainties involved and the potential to cause many losses of lives and economical losses. A primary source of uncertainties in many dam failure analyses refers to prediction of the reservoir's outflow hydrograph, which is studied in the present investigation. This paper presents an experimental study on instantaneous dam failure flood under different reservoir's capacities and lengths in which the side slopes change within a range of $30^{\circ}-90^{\circ}$. Thus, several outflow hydrographs are calculated and compared. The results reveal the role of the side slopes on dam break flood wave, such that lower side slope creates more catastrophic outflow. The reservoir capacity and length are also recognized to be important factors, such that they do affect peak discharge and time to peak of the outflow hydrograph. Finally, the paper presents two simple relations for peak discharge and maximum water level estimation at any downstream location.
\end{abstract}

Keywords. Dam break; experimental study; hydrograph; physical model; reservoir geometry.

\section{Introduction}

Dams are subject to failure because of a variety of causes: landslides, earthquakes, heavy rainfall or other triggering factors. The failure of a dam can threaten people's lives and property downstream [1]. Floods from failure of dams are typically much more devastating than the hydrologic floods from heavy precipitations. A dam break flood has a greater peak-discharge magnitude and a shorter time to peak and base time. The time to peak may have values ranging from only a few minutes to usually no more than a few hours. This makes the dam break flood more complicated to be analysed using common hydraulic rainfall-runoff tools.

The failure mode depends upon the failure cause and dam type [2]. Erodible embankment dams gradually fail mostly because of overtopping and piping, while concrete gravity and arch dams usually fail very fast due to overturning and sliding. In the sudden failure, dam structure is removed abruptly and the stored water is released rapidly to the downstream river valley. The worst condition and the most potential of damages are expected from such a failure mode [2]. Various hydrologic, hydraulic, morphologic and geotechnical factors influence the dam break flow features. To study the role of these factors, experimental and numerical models have been very useful. Numerical-

*For correspondence solution-based models use the governing equations to describe the flow through the breach and spillway and flow over top of the dam, which is followed by routing the flood wave through downstream river. Typically, dam break models are required for breach parameters and outflow hydrograph can be estimated and provided as the inputs of a routing model [3] to produce water levels and flow velocities at downstream locations [4]. Obviously, the higher the accuracy of the input hydrograph, the more precise the expected output. The obtained results significantly affect the ultimate flash flood risk management plan. In order to improve the inputs and advance our knowledge about the effective variables, the physical models have been proven to be effective tools, although they are important for calibration and verification of the numerical models as well. The first documented experimental and analytical dam break studies were published in the 18 th century $[5,6]$. Ritter [6] provided a solution to the instantaneous dam break problem, where there is an infinitely long reservoir connected to a dry frictionless horizontal channel with rectangular cross sections. Dressler developed Ritther solution considering the flow resistance [7]. In another analytical attempt [8], the effect of cross-sectional shape of the channel varying from rectangular to triangular was examined. Analytical methods usually provide explicit solution to the instantaneous dam break problem by applying certain general expressions of the Saint-Venant 
equations. They do not consider partial dam failure, complicated geometry of the reservoir and river valley, and the limited reservoirs length. In recent years, the analytical studies have been replaced with more applied approaches of numerical and experimental modelling.

Based on the numerical solution of shallow water equations (SWEs) for reservoirs of different bathymetries, an approach to the characterization of the hydrographs following partial collapse of a concrete gravity dam was presented [9]. This investigation demonstrated that the reservoir cross section affects the flood magnitude of dam failure. Using a physical model, the effect of the reservoir's shape on the outflow hydrograph following a sudden dam failure was investigated in another work [10]. Also the significant role of the reservoirs' side slopes on the main features of dam break flood wave, i.e., peak discharge, time to peak and the time evolution of the outflow hydrograph, was demonstrated [11]. All these investigations and some others [12-14] have demonstrated that the reservoir's geometry plays an effective role on the reservoir's outflow hydrograph, which is introduced as the basis of hydraulic modelling of dam failure [9]. Considering the massive impact of dam failure on the civilian population, infrastructures and the environment, any attempt that can improve our knowledge about this phenomenon and prediction ability of the predictive tools is invaluable. Despite a great deal of past researches, to the author's knowledge, no comprehensive evaluation of the effect of the reservoir's geometry including length, volume and cross section on dam failure outflow hydrograph has been reported. Therefore, this study aims to investigate this shortage by presenting an experimental attempt on instantaneous dam failure considering various parameters that make an ideal reservoir's geometry. Here actual reservoirs will be used to extract an appropriate geometry applicable to the experimental model, and then the importance of the reservoir in any dam break flood risk management will be shown by a robust flume test. In the next section the methodology of the investigation is described. The third section provides the experimental set-up and apparatus. Section 4 presents the obtained results and finally section 5 provides conclusion and outcomes of the study.

\section{Methodology}

To have a benchmark solution for evaluating the results, the Dressler analytical solution [7] is employed. The Dressler solution proposes Eqs. (1) and (2) [given by Eq. (24) in the original paper] for calculation of velocities of flow and wave, respectively:

$$
\begin{gathered}
\frac{u}{c_{0}}=\frac{2}{3}(1+w)+h(w) T C \\
\frac{c}{c_{0}}=\frac{1}{3}(2-w)+k(w) T C
\end{gathered}
$$

where $c$ is wave velocity $(\mathrm{m} / \mathrm{s}) ; c_{0}=\left(g h_{u}\right)^{0.5}$ is initial wave velocity, where $h_{u}$ is the initial height of water at the reservoir and $g$ is acceleration due to gravity $\left(\mathrm{m} / \mathrm{s}^{2}\right) ; T=t /$ $\left(h_{u} / g\right)^{0.5}$ is dimensionless time, where $t$ is time (s); $C=n^{2} g / R^{1 / 3}$ is dimensionless Chezy resistance term [7], where $R$ is hydraulic radius (m); $n$ is Manning resistance coefficient $\left(\mathrm{s} / \mathrm{m}^{1 / 3}\right)$ and $k(w)$ and $h(w)$ are calculated as follows [given by Eq. (23) in the original paper]:

$$
\begin{gathered}
k(w)=\frac{6}{5(2-w)}-\frac{2}{3}+\frac{4 \sqrt{3}}{135}(2-w)^{3 / 2} \\
h(w)=\frac{-108}{7(2-w)^{2}}+\frac{12}{2-w}-\frac{8}{3}+\frac{8 \sqrt{3}}{189}(2-w)^{3 / 2}
\end{gathered}
$$

where $w=x /\left(t c_{0}\right)$ and $x$ is distance from the dam (m). Note that these equations are valid when $w<2$.

\subsection{Reservoir's geometry}

Generally, in a dam break analysis, initially the outflow hydrograph from the reservoir is estimated and then routed downstream of the river [9]. The outflow hydrograph is affected by various hydraulic and geometric parameters of the reservoir, dam and breach. These parameters define the overall volume and duration of the outflow followed by the collapse of a dam. The reservoir's geometry can be modelled if the reservoir's shape in plan and its cross-sectional profile at any longitudinal distance are available. Several investigations $[8,9]$ have considered a prismatic reservoir with cross-sectional area $(A)$ as

$$
A=\delta h^{\lambda}
$$

where $h$ is the reservoir's depth at each point and $\delta$ and $\lambda$ are constant values that depend on the cross-sectional shape. The $\lambda$ value varies between 1.0 (for rectangular cross section) and 2.0 (for triangular cross section). The $\lambda$ value of 1.5 represents a parabolic cross section. In the laboratory, construction of a parabolic cross section $(1.0<\lambda<2.0)$ is difficult and costly (compared with the polygonal cross sections), although it has been distinguished in the mountain valleys [9]. The present study applies simplifying assumptions to simulate the reservoir cross section as trapezoidal. In figure $1 \mathrm{a}$ and $\mathrm{b}$ the heightarea-volume curves (plotted in non-dimensional form) of two actual mountain reservoirs in Iran (Esteghlal and Saveh reservoirs) are provided and compared to that of an ideal trapezoidal reservoir (figure 1c). Comparison of the curves demonstrates that the trapezoidal cross section can be considered suitable for simulation of a natural mountain reservoir.

For geometric similarity, every trapezoidal reservoir should have a specific side slope equivalent to $\lambda$ of a parabolic cross section of a mountain reservoir. To determine the range of side slopes, it is assumed that the 


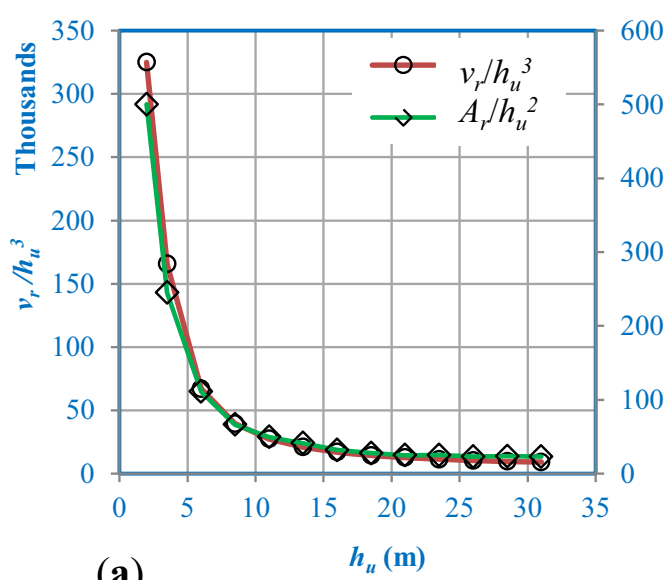

(a)

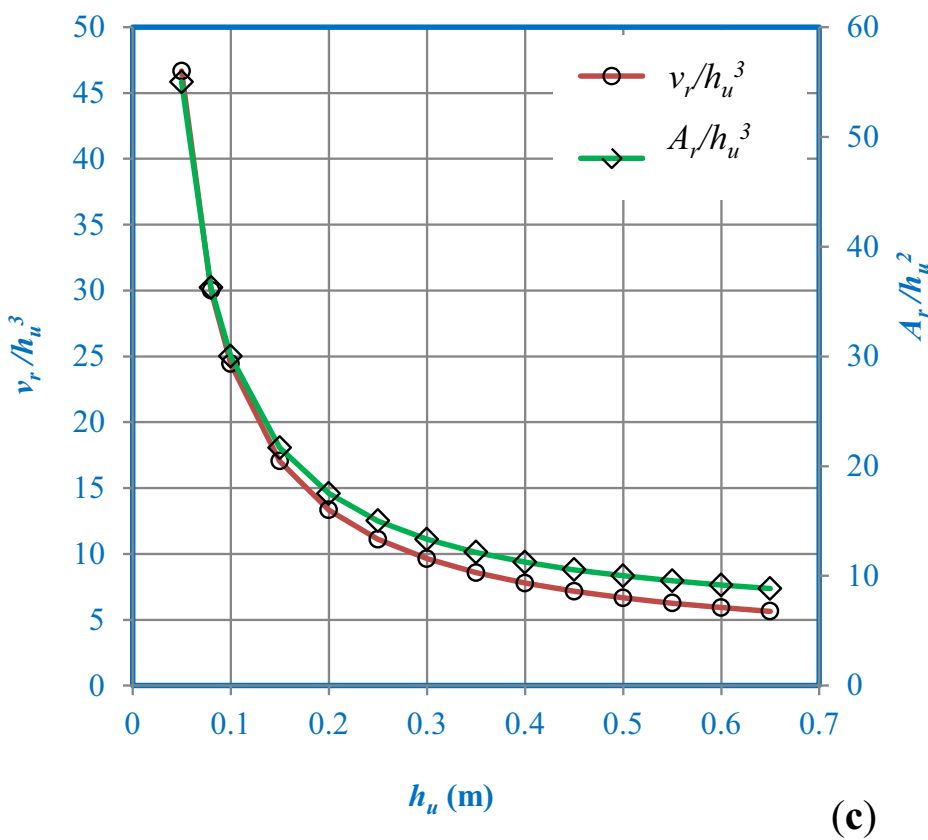

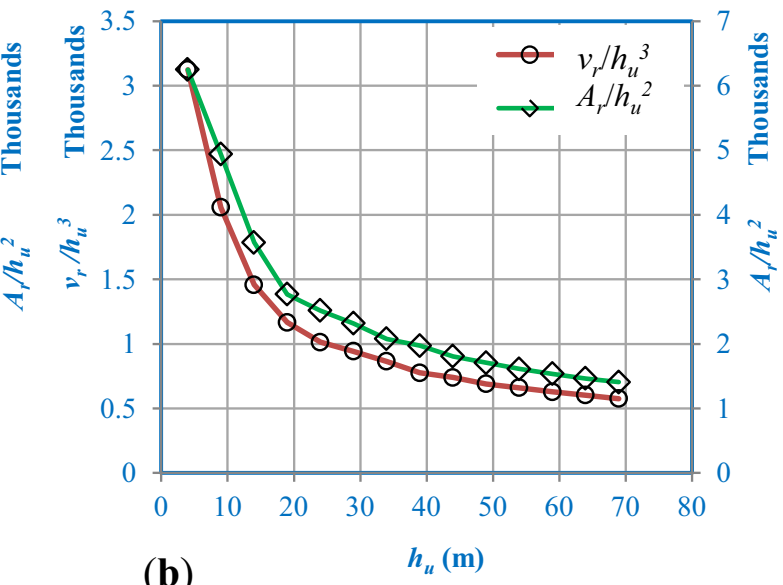

(b)
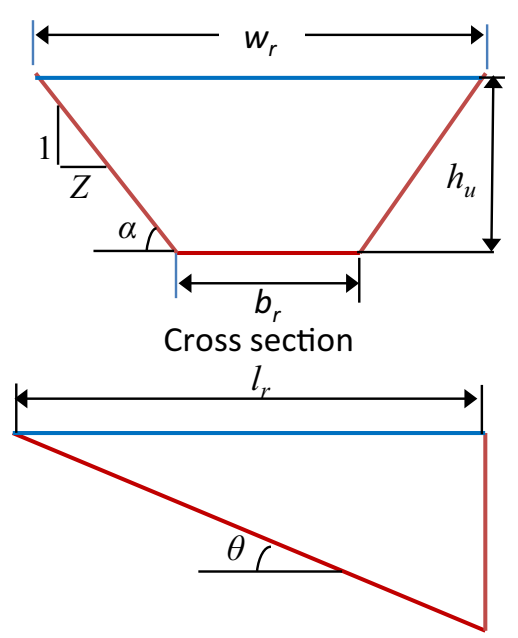

Longitudinal profile

Figure 1. Height-area-volume curve of (a) Esteghlal reservoir, (b) Saveh reservoir and (c) an ideal trapezoidal reservoir with bottom longitudinal slope $\tan \theta=0.1$ and side slopes $\alpha=30^{\circ}\left(h_{u}\right.$ is the height of water behind the dam, $A_{\mathrm{r}}$ is the reservoir area and $v_{r}$ is the reservoir capacity).

hydraulic radius values of the corresponding trapezoidal and parabolic reservoirs are the same; here

$$
\begin{aligned}
& R_{\text {tra }}\left(=\frac{A_{\text {tra }}}{P_{\text {tra }}}\right)=R_{\text {para }}\left(=\frac{A_{\text {para }}}{P_{\text {para }}}\right) \\
& P_{\text {tra }}=b_{r}+\frac{2 h_{u}}{\sin \alpha}, \quad P_{\text {para }}=\int \sqrt{1+f^{\prime}(x)^{2}} d x \\
& A_{\text {tra }}=\left(b_{r}+\frac{h_{u}}{\tan \alpha}\right) h_{u}, \quad A_{\text {para }}=w_{r} h_{u}-\int f(x) d x
\end{aligned}
$$

where $R_{\text {tra }}$ and $R_{\text {para }}$ are the hydraulic radius; $P_{t r a}$ and $P_{\text {para }}$ are the wetted perimeter; and $A_{\text {tra }}$ and $A_{\text {para }}$ are the crosssectional areas of the trapezoidal and parabolic reservoirs, respectively; $b_{r}$ is the bottom width of the trapezoidal reservoir (here it equals $0.51 \mathrm{~m}$ ); $w_{r}$ is the top width of the reservoir; $\alpha$ is the side-slope angle and $f(x)$ is a function of parabola for Pilotti's reservoir. Solving the equation for four side-slope angles of $30^{\circ}, 45^{\circ}, 60^{\circ}$ and $90^{\circ}$, the values of corresponding $\lambda$ are estimated as 1.56, 1.45, 1.38 and 1.0, respectively. Figure 2 illustrates the parabolic cross sections and their equivalent trapezoids.

Considering the length of the reservoirs, two scenarios were defined. In the first scenario to have a logical comparison between the outflow hydrographs, the capacity of the reservoirs (the area under the bell-shape hydrographs) was considered to be the same. In this scenario, when the 

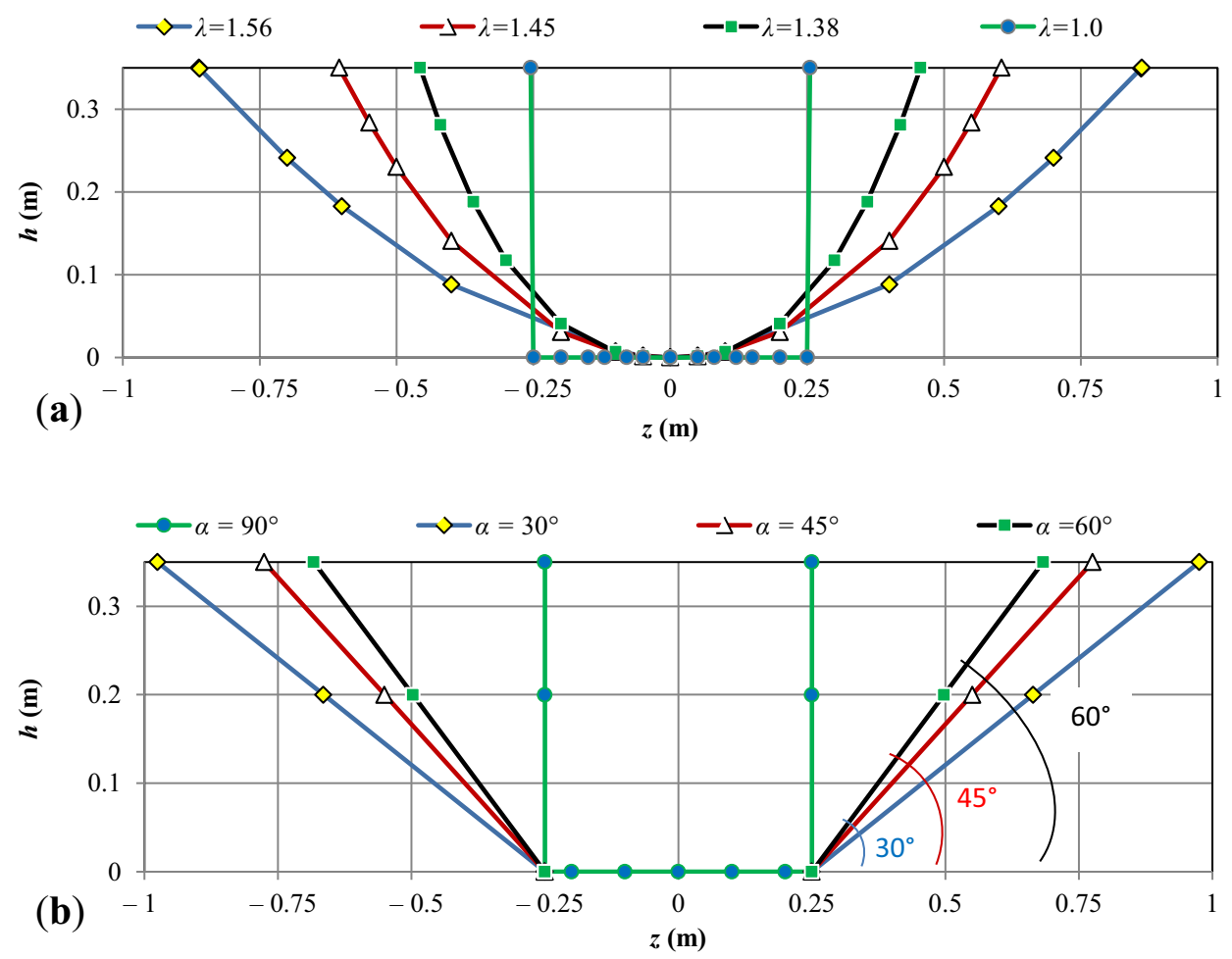

Figure 2. (a) Four considered parabolic cross sections and (b) the equivalent trapezoidal sections.

Table 1. The geometric and hydraulic parameters of the reservoirs.

\begin{tabular}{lcllllllll}
\hline$\alpha\left(^{\circ}\right)$ & $\begin{array}{c}\text { Equivalent } \\
\lambda(-)\end{array}$ & $\begin{array}{c}Z \\
(-)\end{array}$ & $\begin{array}{c}b_{r} \\
(\mathrm{~m})\end{array}$ & $\begin{array}{c}w_{r} \\
(\mathrm{~m})\end{array}$ & $\begin{array}{c}h_{u} \\
(\mathrm{~m})\end{array}$ & $\begin{array}{c}A_{0} \\
\left(\mathrm{~m}^{2}\right)\end{array}$ & $\begin{array}{c}R \\
(\mathrm{~m})\end{array}$ & $\begin{array}{c}l_{r} \\
\left(\text { for fixed } v_{r}=0.803 \mathrm{~m}^{3}\right)(\mathrm{m})\end{array}$ & $\begin{array}{c}v_{r} \\
\left(\text { for fixed } l_{r}=4.5 \mathrm{~m}^{2}\right)\left(\mathrm{m}^{3}\right)\end{array}$ \\
\hline 30 & 1.56 & 1.73 & 0.51 & 1.72 & 0.35 & 0.391 & 0.205 & 2.05 & 1.76 \\
45 & 1.45 & 1.0 & 0.51 & 1.21 & 0.35 & 0.301 & 0.2 & 2.67 & 1.355 \\
60 & 1.38 & 0.58 & 0.51 & 0.91 & 0.35 & 0.249 & 0.189 & 3.23 & 1.121 \\
90 & 1.0 & 0.0 & 0.51 & 0.51 & 0.35 & 0.179 & 0.148 & 4.5 & 0.803 \\
\hline
\end{tabular}

$A_{0}$ and $R$ are the initial wetted area of the dam and hydraulic radius of the reservoir, respectively. The other parameters are introduced in figure 1.

cross-sectional area varies from case to case, the length of the reservoirs was adjusted adequately to keep the capacity unchanged (see table 1, column 9). Conversely, in the second scenario, length of the reservoirs was kept the same; therefore, the volume of the reservoirs will not be the same for different side slopes. The experimental reservoir has limited length; therefore, the outflow hydrograph at any downstream point would be affected by negative wave reflected by the reservoir's upstream wall. The time interval in which the negative wave travels to the upstream wall and then to any measuring points, "time limit" $\left(t_{\text {limit }}\right)$, can be calculated in non-dimensional form by the following equation [15]:

$$
T_{\text {limit }}=\frac{2 L_{r}+X}{C_{n f}}
$$

where $L_{r}=l_{r} / h_{u}$ is non-dimensional length of the reservoir; $X=x / h_{u}$ is the non-dimensional distance of any location to the gate and $C_{n f}=c_{n f} f\left(g h_{u}\right)^{0.5}$ is the non-dimensional negative wave front velocity. Table 1 summarizes the geometric and hydraulic characteristics of the reservoirs that are examined in the present study.

\subsection{Dimensional analysis}

Considering the effective hydraulic parameters as well as rectangular breach width of $w_{b}$ and height $h_{b}$ and that the reservoirs have trapezoidal cross section with top width of $w_{r}$, side slope of $Z$, length of $l_{r}$ and capacity of $v_{r}$, we have 


$$
f_{1}(\underbrace{h_{u}, g, q, t}_{\begin{array}{c}
\text { Hydraulic } \\
\text { parameters }
\end{array}}, \underbrace{Z, l_{r}, v_{r}}_{\begin{array}{c}
\text { Reservoir's } \\
\text { geometry }
\end{array}}, \underbrace{w_{b}, h_{b}}_{\begin{array}{c}
\text { Breach's } \\
\text { geometry }
\end{array}}, \underbrace{x}_{\text {Location }})=0 .
$$

Using Buckingham $\Pi$ theorem with $g$ and $h_{u}$ as the repeating variables, Eq. (8) can be rewritten as

$$
\begin{gathered}
f_{2}\left(\frac{q}{h_{u} \sqrt{g h_{u}}}, \frac{t}{\sqrt{h_{u}}}, Z, \frac{l_{r}}{h_{u}}, \frac{v_{r}}{h_{u}^{3}}, \frac{w_{b}}{h_{u}}, \frac{h_{b}}{h_{u}}, \frac{x}{h_{u}}\right) \\
=f_{2}\left(Q, T, Z, L_{r}, V_{r}, W_{b}, H_{b}, X\right)=0 .
\end{gathered}
$$

In this study $h_{b}=h_{u}$. Hence $H_{b}=1$ and $W_{b}=w_{b} / h_{u}=$ $0.51 / 0.35=1.46$ in all the tests. For peak outflow discharge $\left(Q_{P}\right)$ analysis, $T$ is ignored as peak discharge does not depend upon time. Therefore Eq. (9) is transformed to

$$
f_{3}\left\{Q_{p}, Z, L_{r}, V_{r}, X\right\}=0 .
$$

Similarly, in the case of maximum water level, $H_{\max }=h_{\max } / h_{u}$ can be written as

$$
f_{4}\left\{H_{\max }, Z, L_{r}, V_{r}, X\right\}=0 .
$$

\section{Experimental set-up and apparatus}

Figure 3 illustrates the experimental set-up that is located in the Hydraulics Laboratory of Civil Engineering Department, Amirkabir University of Technology, Iran. The upstream reservoir is $4.5 \mathrm{~m}$ long and $2.25 \mathrm{~m}$ wide and is made of galvanized sheet of $2 \mathrm{~mm}$ thickness. The rectangular flat and horizontal flume at downstream has dimensions of $0.51 \mathrm{~m}$ width, $0.7 \mathrm{~m}$ height and $9.3 \mathrm{~m}$ length. A gate separating the reservoir and the flume can be opened instantaneously with the aid of a pneumatic jack. The downstream end of the channel works as a free drop. To minimize the interference of the gate and water, the gate is made of a Plexiglas plate with $10 \mathrm{~mm}$ thickness. In this study the value of $h_{u}$ is $0.35 \mathrm{~m}$ above the reservoir bottom and the flume is initially dry. Considering Vischer and Hager [16], the dam break simulation is instantaneous because the gate opening time $\left(t_{o p}=0.14 \mathrm{~s}\right)$ is less than the critical time $t_{c r}=1.25 \sqrt{h_{u} / g}=0.24 \mathrm{~s}$. Temporal water level evolution is recorded at different stations by means of six ultrasonic sensors (with an accuracy of $\pm 0.12 \mathrm{~mm}$ ) and the velocity components are acquired by a SonTec Micro-Acoustic Doppler Velocimeter (ADV) (with response frequencies up to $50 \mathrm{~Hz}$ ) [17]. All the ultrasonic sensors are installed above the flume on a movable rail at the top centre of the channel.

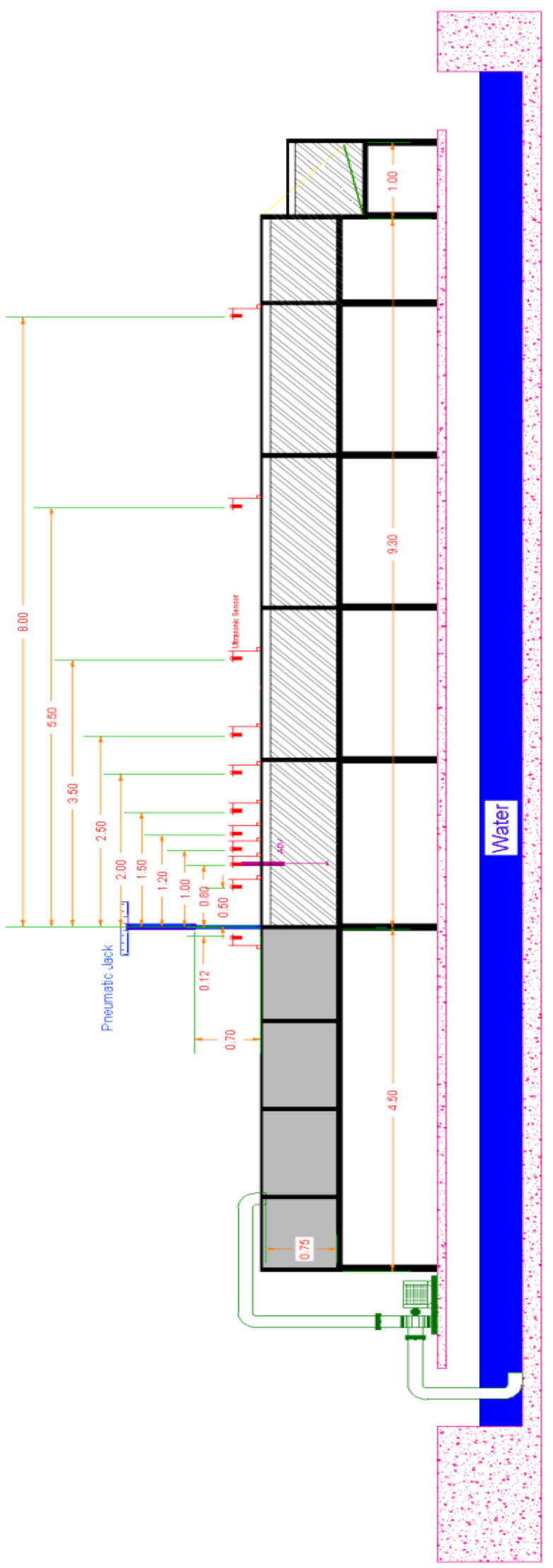

Figure 3. Sectional view of the experimental set-up (measures are in metre). 


\section{Results and discussion}

\subsection{Comparison with Dressler's analytical solution}

In this section, initially, the measured water levels $(h)$ and velocities $(u)$ for the reservoir with $4.5 \mathrm{~m}$ length and $90^{\circ}$ side slope are presented and compared with the Dressler solution. A view of the reservoir, the gate and the employed structures for stabilizing the walls is presented in figure 4a.

Once the gate is opened, the water resting in the reservoir flows downstream and the installed ultrasonic sensors record the flow level. An ultrasonic sensor is located in the reservoir $(X=-0.343)$ and the others are located across the downstream channel from $X=0.571$ to 22.86 . Figure 5 illustrates the temporal variation of water depth at four locations, compared to the Dressler solution. It is shown that the water level at $X=-0.343$ falls down to $H=h$ / $h_{u} \sim 0.48$ immediately after the gate removal, and later continues with a negligible variation between $T=5.3$ and 21.0. It again starts to fall down as soon as the reflected negative wave reaches this point (at the time limit shown by a dashed line in the figure). In the downstream locations, water level rises as the wave front arrives and rapidly reaches its maximum value, and later gradually falls down in the time limit. It can be seen that the maximum level decreases at farther downstream locations. Figure 5 also includes Dressler's solution at the same locations. The analytical curves are calculated from Eq. (2) for the corresponding $X$ and $T$ under constant $C(=0.0022)$ by transforming the wave celerity to water level $\left(H=h / h_{u}=c / c_{0}\right)$. As seen, the experimental curves deviate away from the corresponding analytical curves at the time limit, because the Dressler solution supposes an infinite length for the reservoir; thus, no reflected negative wave is expected and the reservoir will never empty. Furthermore, figure 5
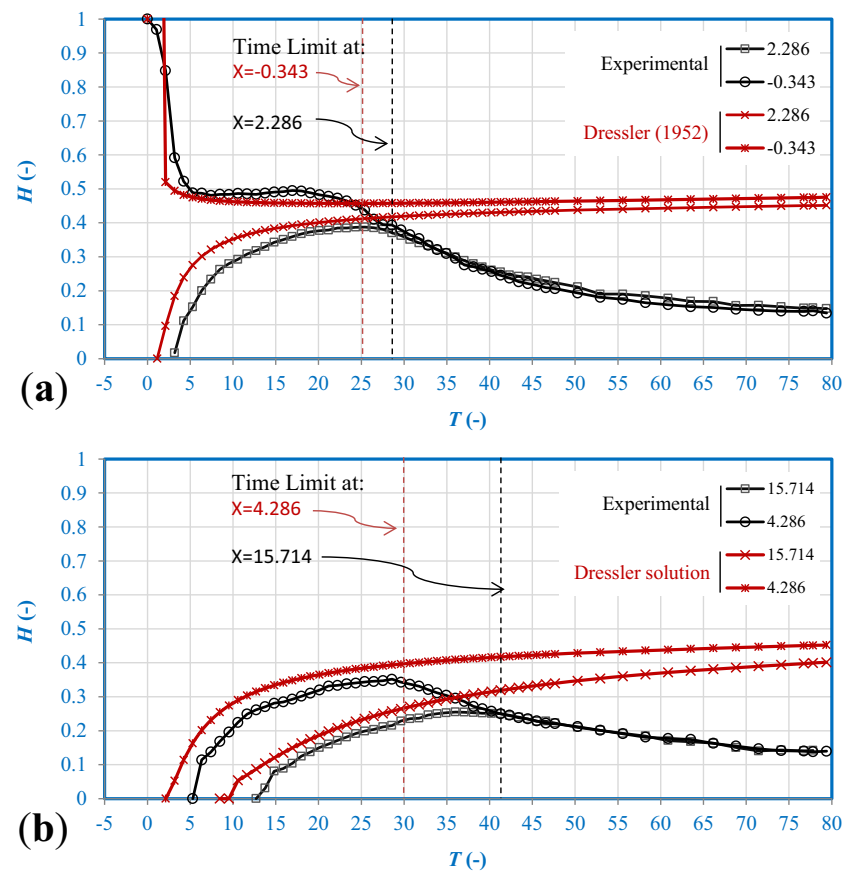

Figure 5. Dam break flow depth from $90^{\circ}$ side-slope reservoir at (a) $X=-0.343$ and $X=2.286$ and (b) $X=4.286$ and $X=15.714$ in comparison with Dressler analytical solution.

indicates that the analytical wave arrives at any downstream location faster than the experimental wave. Indeed, the analytical solution has been developed for an ideal flow in a wide rectangular channel and it does not take in to account the effect of walls' resistance and the influence of gate removal [18]. Moreover, experimental studies have showed that the wave celerity in a natural rough-bed valley could be lower than that achieved by the Dressler solution [19]. The strong aeration of the wave front can cause
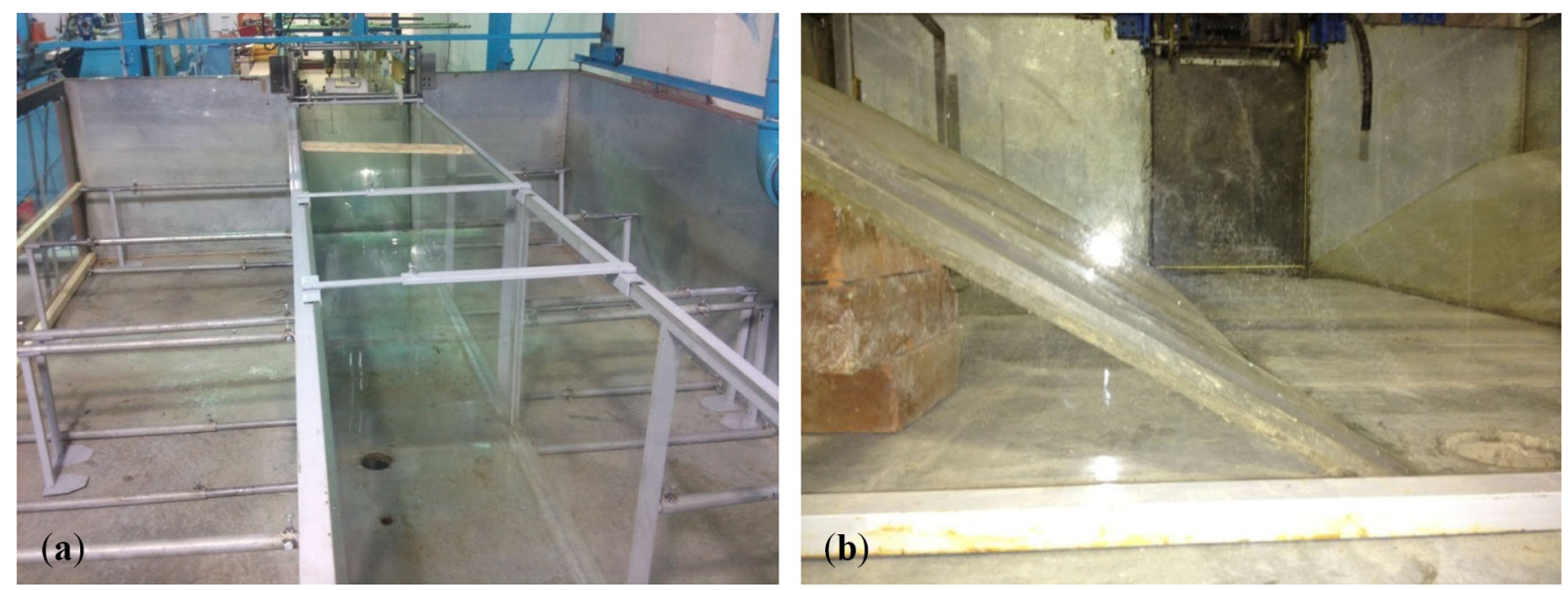

Figure 4. Photo of the reservoirs in the laboratory with (a) $90^{\circ}$ side slope and (b) $30^{\circ}$ side slope. 


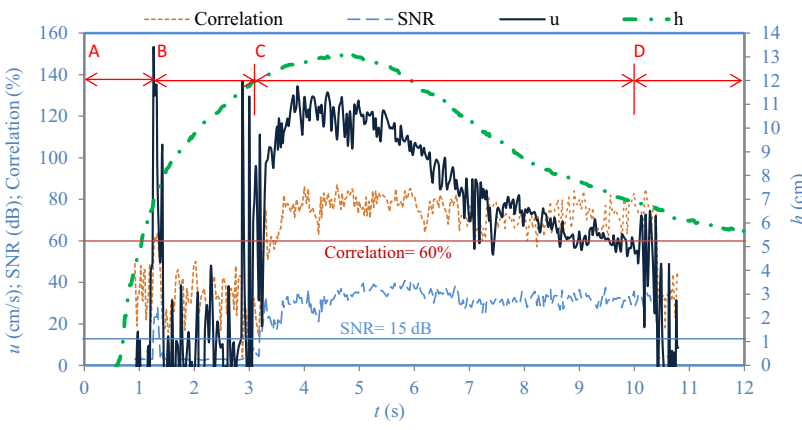

Figure 6. Data acquired from ultrasonic sensor (water level) and ADV (velocity) at $X=2.286$ and $Y=0.2$.

discrepancy between the experimental and the analytical solutions [19].

The quality of ADV data in the velocity time series was monitored by two criteria: signal strength of the probes and correlation factor. Accordingly, the Doppler noise and spikes were detected and filtered when signal to noise ratio (SNR) was less than $15 \mathrm{~dB}$ or correlation was less than $60 \%$ [17]. Figure 6 illustrates the acquired velocities from ADV when the probe is installed $7 \mathrm{~cm}$ above the channel bottom $\left(Y=y / h_{u}=0.2\right)$ at $X=2.286$ as well as the water level from the ultrasonic sensor at the same location. The ADV probe is submerged when the water level exceeds $7 \mathrm{~cm}$ (corresponding to point $\mathrm{B}$ in figure 6); in this case the $\mathrm{ADV}$ records satisfy the quality criteria at point $\mathrm{C}$ till the probe dries again at point D. Figure 6 also includes SNR and correlation temporal variations as well as two horizontal lines regarding the quality criteria $(\mathrm{SNR}=15 \mathrm{~dB}$ and correlation $=60 \%$ ).

The recorded velocities at various depths are smoothed after spikes removal and later the average velocity is calculated. Figure 7 shows the calculated average velocities at downstream locations. The maximum velocity has been recorded as $U=u / \sqrt{g h_{u}}=0.77$ at $T=13.34$, and the earlier velocities have been discarded because they do not satisfy the quality criteria. However, the Dressler solution is available for this interval. The figure also shows an oscillatory behaviour in later intervals when the flow depth decreases. Note that the value of velocity at time $T$ is calculated as the average of the velocities recorded by the ADV at different depths (points with $10 \mathrm{~mm}$ intervals from the minimum distance of ADV probe installation above the channel bed).

Multiplying water levels with the corresponding velocities gives the discharge hydrograph (figure 8). As the velocity is not available in the early intervals, the first part of the hydrographs is shown by dashed lines in the figure.

\subsection{Reservoir with side slope}

Other than the $90^{\circ}$ side-slope reservoir that was described earlier, six other reservoirs with different side slopes (either
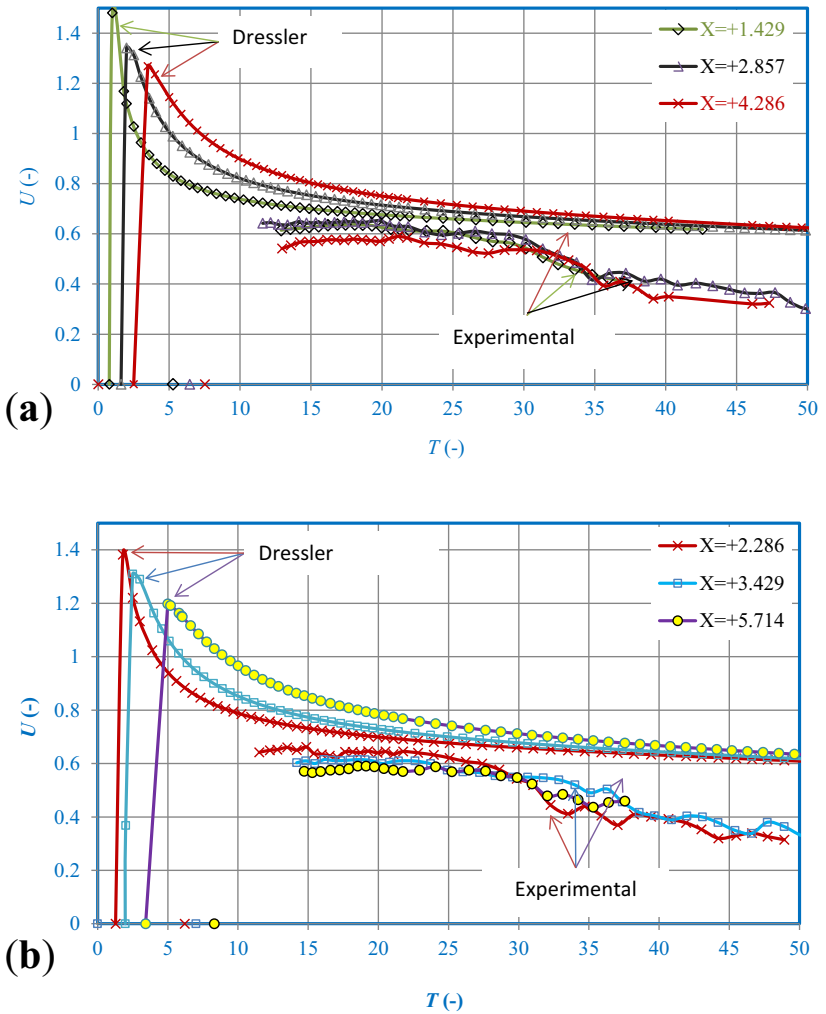

Figure 7. Dam break velocity from the $90^{\circ}$ side-slope reservoir at (a) $X=1.429, X=2.857$ and $X=4.286$ and (b) $X=2.286$, $X=3.429$ and $X=5.714$ in comparison with the Dressler solution.

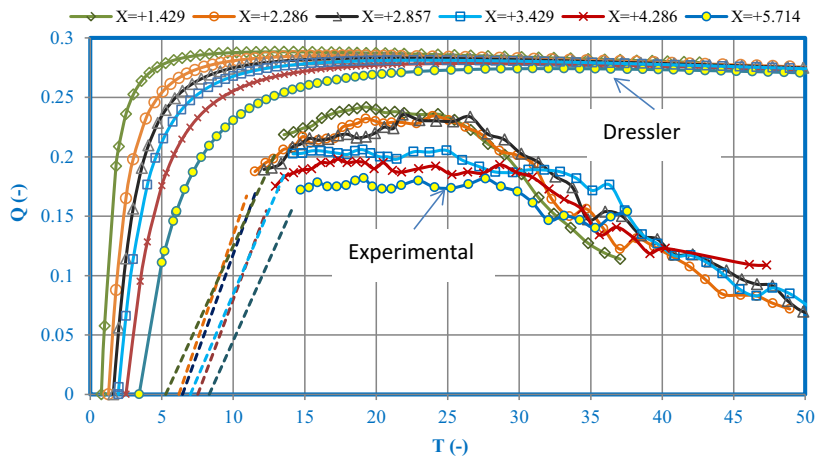

Figure 8. Discharge variations at downstream locations of $90^{\circ}$ side-slope reservoir in comparison with the Dressler solution.

with equal capacity of $V_{r}=18.73$ or equal length of $L_{r}=12.85$ ) were examined. A view of the $30^{\circ}$ reservoir is shown in figure $4 \mathrm{~b}$. Figure 9 illustrates the water level variation at the reservoir $(X=-0.343)$ and two downstream stations ( $X=1.429$ and 2.286). In the figure, temporal water level variation for the reservoirs with the same capacity (left graphs) and length (right graphs) is compared. Time limits are shown by dashed line in the figures. At the reservoir station $(X=-0.343)$, the water level falls down rapidly and significantly as soon as the negative wave 

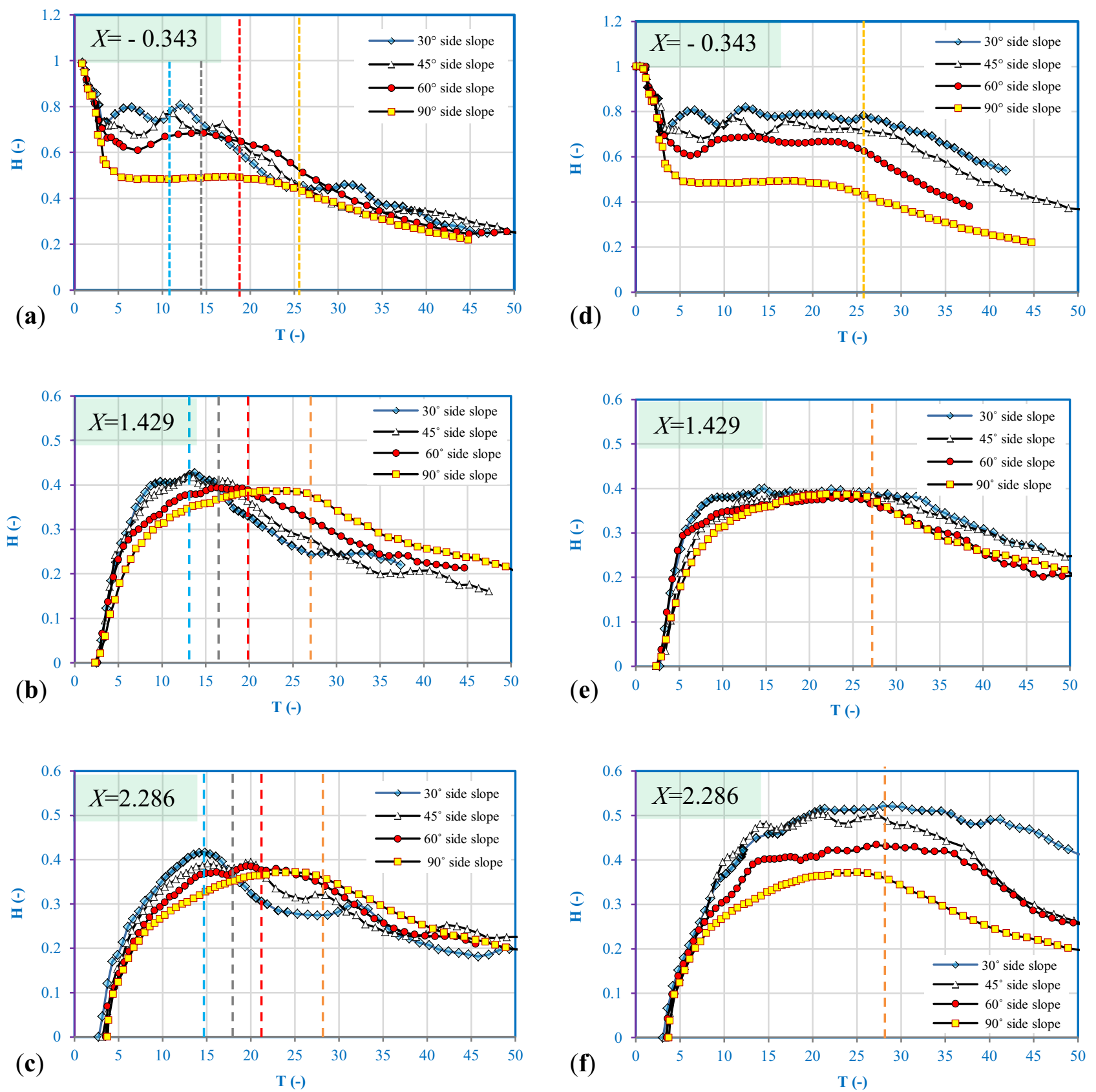

Figure 9. Water level variation at $X=-0.343, X=1.429$ and $X=2.286$ for the reservoirs with (a)-(c) the same capacity and (d)-(f) the same length.

arrives and later oscillates around a specific value for some time till the negative wave comes back to the station at the time limit. For the reservoirs with lower side slope, higher water level is observed, whereas for the equal-capacity reservoirs the maximum water level has a short duration (figure 9a, d). Moreover, because of the lateral wave propagation in the reservoir, water level oscillates periodically and later gets gradually damped. Oscillation with higher amplitude and shorter time period is seen for the reservoirs with lower side slope. At the downstream locations, it can be seen that water level rises rapidly, continues at the maximum level for some time and starts decreasing by the arrival of reflected negative wave. At $X=1.429$ the maximum value is $H \approx 0.4$ for both groups of the reservoirs but it continues to be sustained for some time in figure $9 \mathrm{e}$. As seen from figure $9 \mathrm{c}$ and $\mathrm{f}$, the situation is different at $X=2.286$ such that for the equal-capacity reservoirs, $H$ varies between 0.37 and 0.42 , while for the equal-length reservoirs it varies between 0.37 and 0.52 . Such a condition is observed at the other downstream 

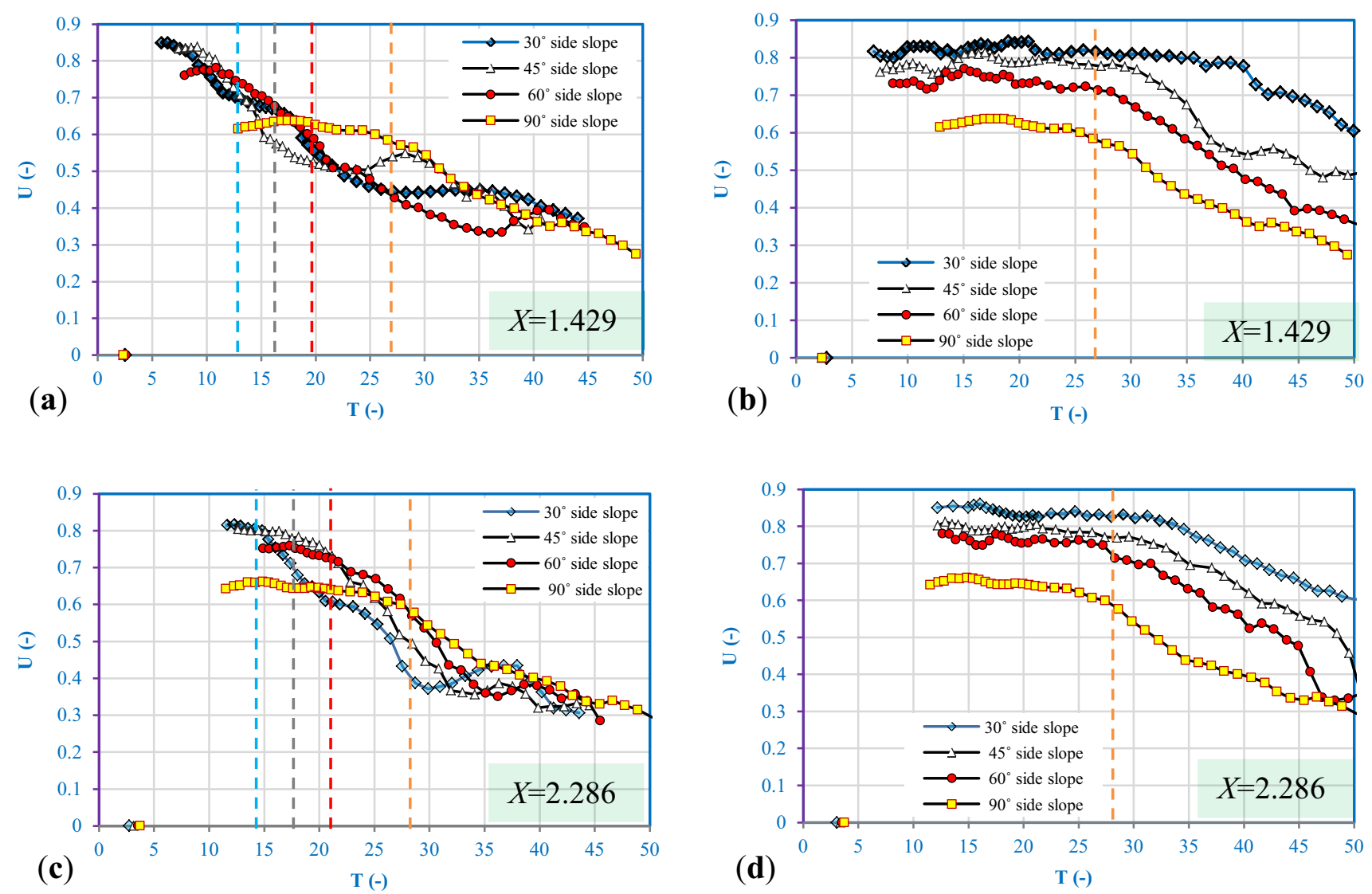

Figure 10. Velocity variation at $X=1.429$ and $X=2.286$ for $(\mathbf{a}, \mathbf{b})$ the reservoirs with the same capacity and (c, d) the same length.

locations. Figure $9 \mathrm{~b}$ and $\mathrm{c}$ shows an oscillatory behaviour in water level due to effect of lateral water waves in the reservoirs, which are more frequent and stronger in the reservoirs with less side slopes. The lateral waves can be seen easily in the $30^{\circ}$ side slope reservoir, but are not seen in the $90^{\circ}$ side-slope reservoir.

Figure 10 illustrates the velocity time series at two downstream locations of the channel. It is observed that the velocity of $30^{\circ}$ side-slope reservoir is higher than those of the other reservoirs. As the side slope increases, the velocity decreases. The length has no significant influence on the maximum velocity except that the maximum value lasts for more time for the larger reservoirs. According to figure 10 , the oscillation of water in the reservoir due to the lateral waves causes an oscillatory behaviour of the velocity time series for $30^{\circ}, 45^{\circ}$ and $60^{\circ}$ side-slope reservoirs. When the wave propagates downstream, these oscillations are gradually damped.

Figure 11 illustrates discharge time series for different reservoirs at $X=1.429$ and 2.286. It can be inferred from this figure that the reservoir capacity, length and side slopes can affect the outflow hydrographs. When the capacity is constant, reservoirs with less side slope produce sharper hydrograph with greater peak value and shorter time to peak. In figure $11 \mathrm{a}, Q_{p}$ for $30^{\circ}, 45^{\circ}$ and $60^{\circ}$ side-slope reservoirs are, respectively, $32 \%, 33 \%$ and $19 \%$ more and their times to peak are, respectively, 55\%, 54\% and $40 \%$ earlier than those of $90^{\circ}$ side-slope reservoir. This situation can be seen at any downstream location. Remember that in figure $11 \mathrm{a}$ and $\mathrm{b}$ the areas under the $Q_{p}$ curves are equal as the reservoirs' capacity has been considered to be the same. Figure 11c shows that the peak discharges from the reservoirs with the same length are approximately similar to those of figure $11 \mathrm{a}$, so that the length does not significantly affect the peak discharge at $X=1.429$, although, it does affect the duration of the peak value in the discharge time series. On the contrary, a significant difference between the peak discharges at $X=2.286$ is observed. According to figure $11 \mathrm{a}$ and $\mathrm{b}$, there are $27 \%, 34 \%$ and $14 \%$ differences between peak discharge of, respectively, $30^{\circ}, 45^{\circ}$ and $60^{\circ}$ side-slope reservoirs and that of $90^{\circ}$ side-slope reservoir. Such a difference is much more visible in figure $9 \mathrm{~d}$.

Furthermore, figure 11a and $\mathrm{b}$ shows that with the same reservoir's capacity, faster reservoir's emptying is expected when the centroid of the volume is closer to the outlet. The reservoir with $30^{\circ}$ side slope has the highest cross-sectional area and the lowest length among the experimental reservoirs and, therefore, the centroid of the volume is very 

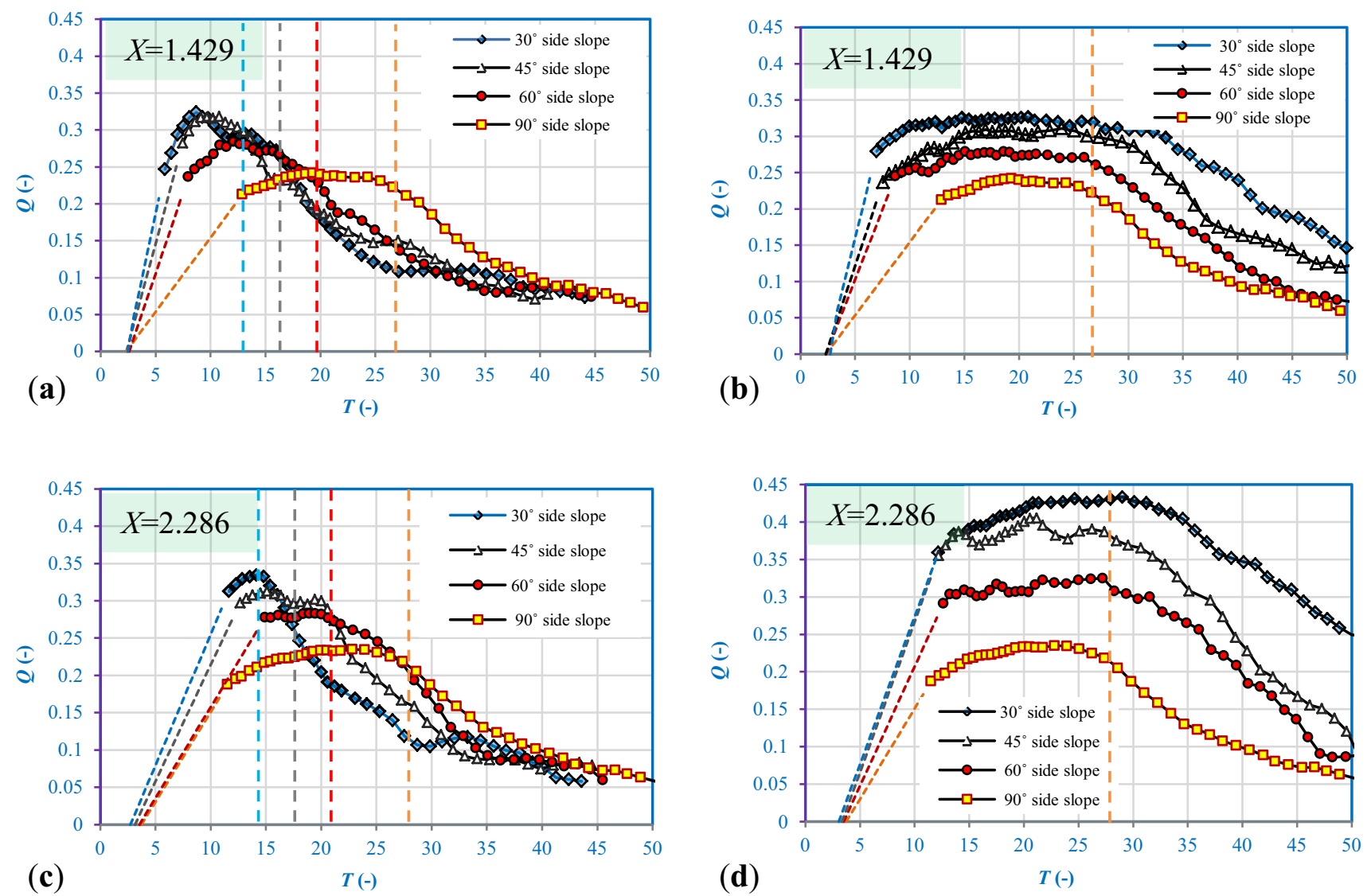

Figure 11. Discharge variation at $X=1.429$ and $X=2.286$ for the reservoirs with $(\mathbf{a}, \mathbf{b})$ the same capacity and (c, d) the same length.

close to the outlet; thus, a higher peak discharge and the earliest time to peak are experienced in this case. Accordingly, as an effective factor on the outflow, the nearer the distance of the reservoir's centroid to the outlet, larger the catastrophic flood, resulting in higher expected risk.

Figure 12 illustrates the flow regime base on the Froude Number (Fr) in the experiments. It is seen that the flow is supercritical initially and then transforms to subcritical as the flow in the channel calms down and the reservoir gets empty gradually.

\subsection{Analysis of the results}

In this section, the maximum water level and discharge values at downstream locations are analysed. Table 2 summarizes the results at four locations for seven experimental reservoirs either with the same capacity or the same length. Note that because of the low flow level and high fluctuation of flow for $X>5.714$, the ADV data did not satisfy the quality criteria and, therefore, the velocity and discharge values are not included in the table for $X=10.0$ and 15.714. The duration of the ADV submergence was found to be shorter and the quality of the acquired data was too low to be of any use at downstream locations.
Applying non-linear regression analysis to these data on the basis of the effective parameters $Z, L_{r}$ and $V_{r}$ at different locations $X$ and Eqs. (10) and (11), the $H_{\max }$ and $Q_{p}$ can be estimated from the following equations:

$$
\begin{gathered}
H_{\max }=\frac{0.336(Z+0.535)^{0.125}}{(X+3.70)^{0.221}} L_{r}^{0.104} V_{r}^{0.092} \\
Q_{p}=\frac{0.197(Z+2.25)^{0.029}}{(X+2.47)^{0.346}} L_{r}^{-0.411} V_{r}^{0.587} .
\end{gathered}
$$

The relations show that the values of $H_{\max }$ and $Q_{p}$ inversely depend on the side slopes $(1 / Z)$. Therefore, for a reservoir with lower side slope, a higher outflow discharge and water level at downstream are expected. Moreover, $X$ factor is in the denominator; therefore, as the flood wave propagates downstream, the peak values of discharge and maximum water level gradually decrease. The volume and length of the reservoirs are also important factors.

It should be noted that when Eqs. (12) and (13) are utilized, users should be aware of the uncertainties associated with these equations, because they have been developed considering various simplifications based on the limited data of a few effective variables. Equations (12) and (13) 

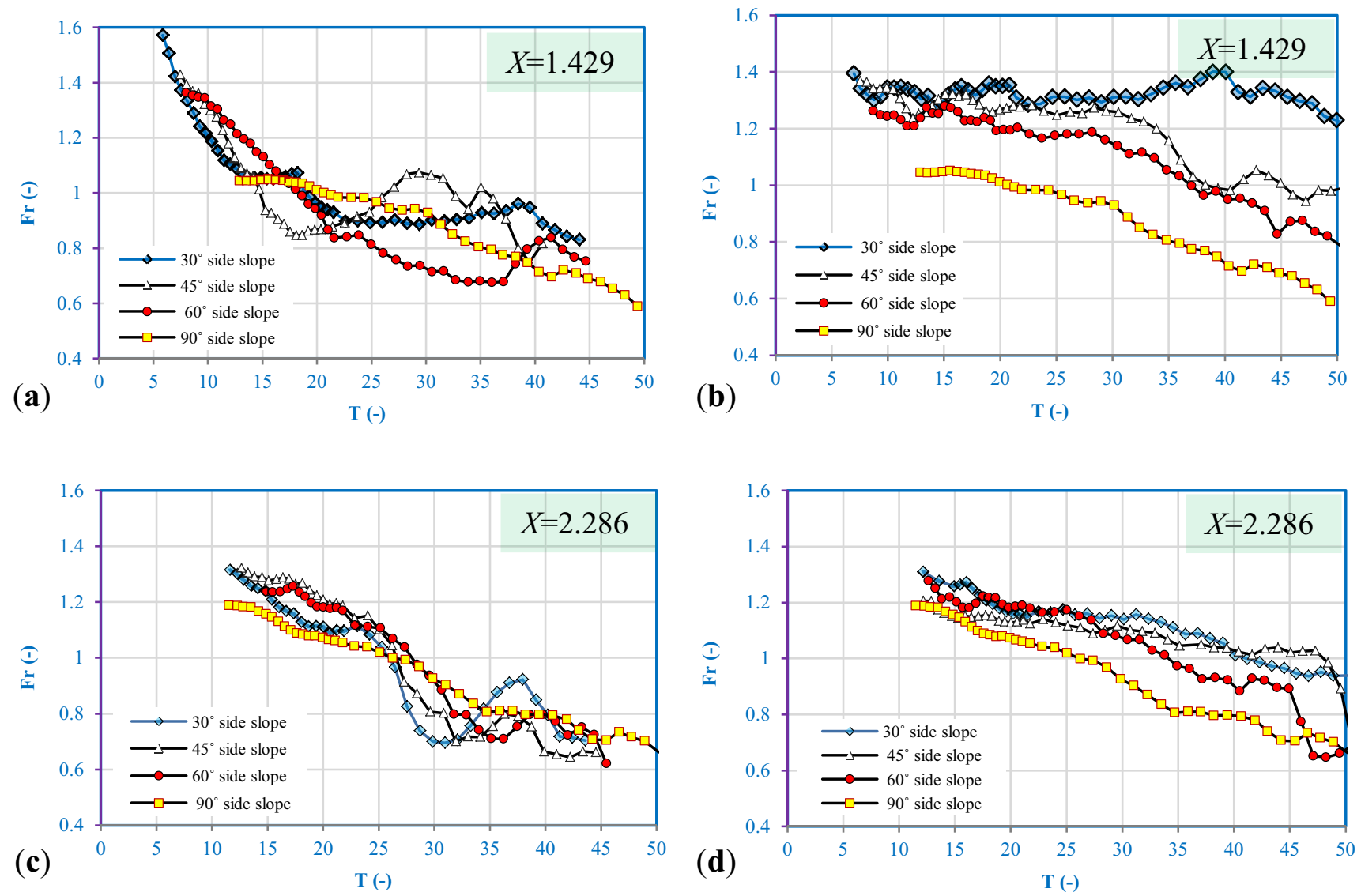

Figure 12. The flow Froude Number at $X=1.429$ and $X=2.286$ for the reservoirs with (a, b) the same capacity and (c, d) the same length.

Table 2. Summary of outflow characteristics from the experimental reservoirs.

\begin{tabular}{|c|c|c|c|c|c|c|c|c|}
\hline \multirow[b]{3}{*}{$X$} & \multirow[b]{3}{*}{ Variable } & \multicolumn{7}{|c|}{ Side slopes } \\
\hline & & \multirow[b]{2}{*}{$90^{\circ}$} & \multicolumn{3}{|c|}{ Fixed $V_{r}(=18.73)$} & \multicolumn{3}{|c|}{ Fixed $L_{r}(=12.86)$} \\
\hline & & & $30^{\circ}$ & $45^{\circ}$ & $60^{\circ}$ & $30^{\circ}$ & $45^{\circ}$ & $60^{\circ}$ \\
\hline \multirow[t]{4}{*}{1.429} & $H_{\max }$ & 0.386 & 0.427 & 0.42 & 0.39 & 0.40 & 0.39 & 0.378 \\
\hline & $T_{H \max }$ & 24.3 & 13.73 & 13.02 & 16.24 & 14.19 & 19.3 & 22.6 \\
\hline & $Q_{p}$ & 0.241 & 0.32 & 0.317 & 0.284 & 0.32 & 0.31 & 0.279 \\
\hline & $T_{Q p}$ & 19.37 & 8.69 & 9.13 & 12.07 & 14.1 & 15.7 & 18.59 \\
\hline \multirow[t]{4}{*}{2.286} & $H_{\max }$ & 0.371 & 0.412 & 0.37 & 0.382 & 0.521 & 0.5 & 0.434 \\
\hline & $T_{H \max }$ & 25.07 & 13.53 & 16.12 & 18.92 & 27.95 & 27.37 & 27.23 \\
\hline & $Q_{p}$ & 0.235 & 0.334 & 0.313 & 0.283 & 0.425 & 0.419 & 0.322 \\
\hline & $T_{Q p}$ & 22.81 & 14.12 & 15.09 & 19.46 & 20.84 & 21.17 & 21.74 \\
\hline \multirow[t]{4}{*}{3.428} & $H_{\max }$ & 0.351 & 0.38 & 0.365 & 0.4 & 0.439 & 0.386 & 0.377 \\
\hline & $T_{H \max }$ & 20.62 & 9.87 & 21.41 & 21.5 & 9.32 & 25.5 & 26.12 \\
\hline & $Q_{p}$ & 0.197 & 0.303 & 0.268 & 0.251 & 0.323 & 0.264 & 0.255 \\
\hline & $T_{Q p}$ & 14.84 & 11.54 & 11.08 & 14.67 & 11.11 & 11.84 & 12.05 \\
\hline \multirow[t]{4}{*}{5.714} & $H_{\max }$ & 0.34 & 0.36 & 0.35 & 0.33 & 0.41 & 0.376 & 0.356 \\
\hline & $T_{\text {Hmax }}$ & 27.6 & 18.7 & 17.9 & 17.86 & 28.01 & 28.15 & 28.716 \\
\hline & $Q_{p}$ & 0.165 & 0.253 & 0.242 & 0.195 & 0.323 & 0.249 & 0.214 \\
\hline & $T_{Q p}$ & 18.54 & 15.06 & 16.72 & 17.28 & 19.59 & 17.05 & 14.7 \\
\hline \multirow[t]{2}{*}{10.0} & $H_{\max }$ & 0.29 & 0.307 & 0.31 & 0.32 & 0.419 & 0.385 & 0.323 \\
\hline & $T_{\text {Hmax }}$ & 32.24 & 24.89 & 24.15 & 26.56 & 31.13 & 28.19 & 33.0 \\
\hline \multirow[t]{2}{*}{15.714} & $H_{\max }$ & 0.254 & 0.281 & 0.318 & 0.276 & 0.369 & 0.347 & 0.287 \\
\hline & $T_{\text {Hmax }}$ & 35.58 & 23.4 & 23.95 & 31.75 & 36.99 & 34.44 & 27.67 \\
\hline
\end{tabular}


Table 3. Statistical indices of the empirical equations.

\begin{tabular}{lccc}
\hline Relation no. & $R^{2}$ & RMSE & AE (\%) \\
\hline$(12)$ & 0.77 & 0.029 & 0.52 \\
$(13)$ & 0.71 & 0.028 & 1.26 \\
\hline
\end{tabular}

introduce dam break wave propagation through a direct rectangular channel characterized by a very low uniform roughness with no slope and meander. It is obvious that wave attenuation is highly influenced by channel irregularities and channel roughness, as the dam break flood waves are expected to spill over the main channel into the floodplains, which are characterized by highly variable large roughness values and, thereby impact the flood peaks and their arrival times at different locations in the downstream channel. On the other hand, the presented equations are very easy to apply because they require a few independent variables and after some algebraic jugglery the main parameters of flood wave can be estimated at important downstream locations such as populated areas, where industrial and agricultural activities thrive. Therefore, such equations are usually useful for rough estimates of hazard magnitude and primary flood risk management.

Performance of the equations was evaluated by three statistical indices, Root Mean Square Error (RMSE), Average Error (AE) and coefficient of determination $\left(R^{2}\right)$, and the results are provided in table $3 . R^{2}$ values are satisfactory for both equations and the RMSE values are also acceptable. In addition, both the equations have insignificant $\mathrm{AE}$ and according to the positive values they are a little overestimating.

Figure 13 illustrates the performance of Eqs. (12) and (13) for estimation of dam failure outflow parameters at the downstream channel. The estimated values in different locations are shown by distinctive marks and colours.

\section{Conclusions}

This paper presented an experimental study of the instantaneous dam break flow by evaluation of the effect of reservoir geometry. The main geometrical parameters investigated here are the side slope, reservoir length and its capacity. Two scenarios were considered for the analysis, one with the equal-capacity reservoirs $\left(V_{r}=\right.$ 18.73) and the other with the equal-length reservoirs $\left(L_{r}=12.86\right)$. In both scenarios, different side slopes of $30^{\circ}, 45^{\circ}, 60^{\circ}$ and $90^{\circ}$ were examined. During the tests, the time series of water level and velocity were recorded, respectively, using an ultrasonic sensor and ADV at several locations of the reservoir and downstream channel. Then the time series of the discharge and flow regime at downstream locations were determined and compared. The inferences made from the analysis of the results can be summarized as follows:
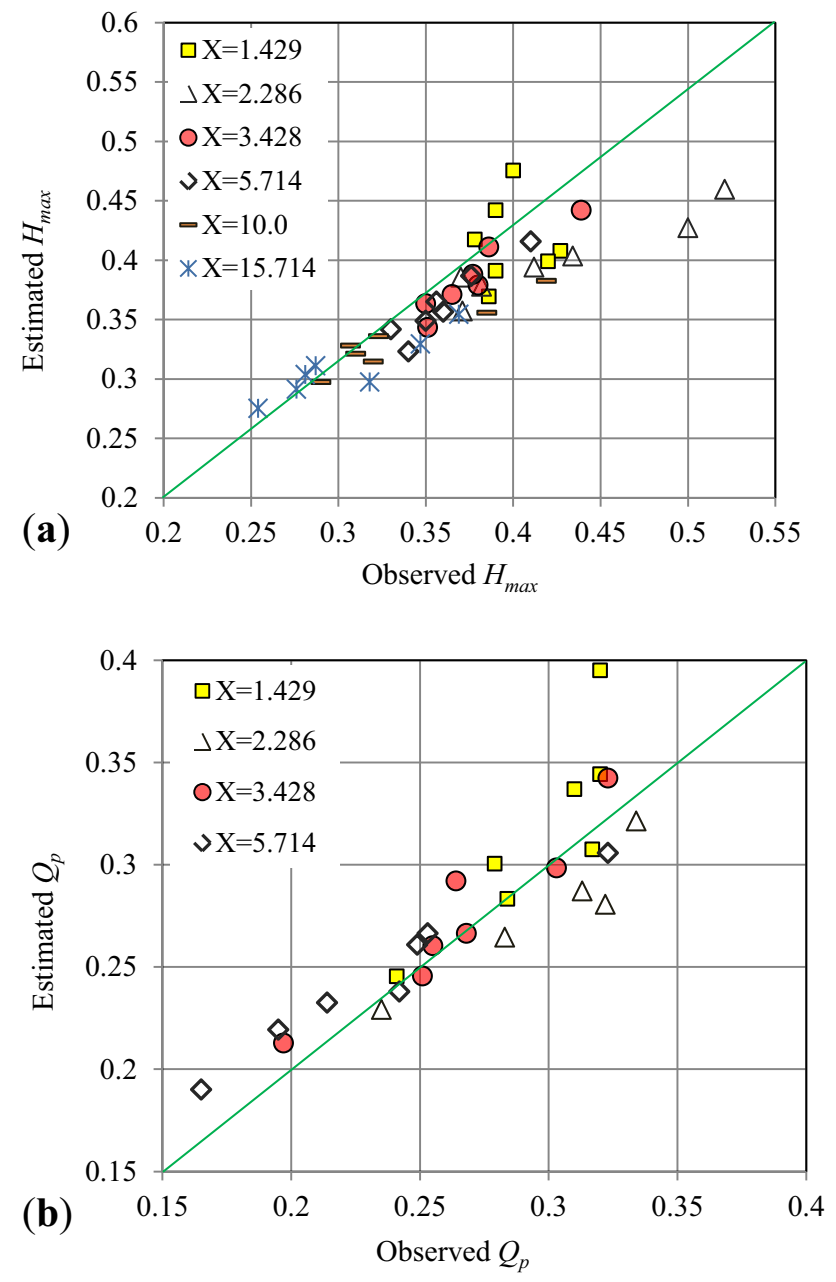

Figure 13. Scatter plot of the observed (a) maximum water level and (b) maximum discharge against the estimated values by Eqs. (12) and (13).

1. Influence of the reservoir parameters on the outflow hydrograph was found to be significant and the main effective parameters were found to be the reservoir's length, capacity and side slopes. Peak outflow discharge and maximum water level increase as the side slope (1/Z) decreases. Moreover, by increasing the volume and/or length of the reservoir (in dimensional form), the values of $H_{\max }$ and $Q_{p}$ are expected to increase.

2. Influence of the reservoir on the outflow hydrograph gradually attenuates along the channel end. Meanwhile, length and volume of the reservoir play significant roles on the wave attenuation, such that for a longer reservoir with higher capacity, the differences between the outflow hydrographs live up to the end of the channel while for the shorter reservoirs with smaller capacities the differences are vanished sooner.

3. Results emphasized that the reservoir's geometry is necessary to be considered in any dam break flood risk management. In conventional dam failure analysis, the hydraulic parameters of the reservoir (height and volume 
of water) enter the analysis, but the main geometric features of the reservoir are neglected. This paper showed that side slope and length are also important; however, the outflow from the reservoir does depend on the uncertain breach size and flow condition through the breach [20].

4. Results showed that the analytical solution of Dressler is valid before the negative wave affects the flood wave flow at downstream. Also, the Dressler solution is not applicable in the early times when the water level falls down rapidly at the moment of the gate removal, because it does not consider the gate removal effect and initial flow perturbations. This leads to faster wave arrival to downstream locations compared with the experimental wave. Besides, in the presence of the cross-sectional waves, which were formed in the case of partial failures (here, for side slope rather than $90^{\circ}$ ), the Dressler solution does not lead to acceptable results.

\section{References}

[1] Xu F, Yang X and Zhou J 2015 Experimental study of the impact factors of natural dam failure introduced by a landslide surge. Environ. Earth Sci. 74(5): 4075-4087

[2] Singh V 1996 Dam breach modelling technology. Dordrecht: Kluwer

[3] Wahl T L 2004 Uncertainty of predictions of embankment dam breach parameters. J. Hydraul. Eng. 130(5): 389-397

[4] Thornton C I, Pierce M W and Abt S R 2011 Enhanced predictions for peak outflow from breached embankment dams. J. Hydrol. Eng. 16(1): 81-88

[5] Bazin H 1865 Recherches Expérimentales relatives aux remous et à la propagation des ondes [Experimental research on the hydraulic jump and on wave propagation]. Deuxième partie des Recherches hydrauliques de Darcy et Bazin, p 148

[6] Ritter A 1892 Die Fortpflanzung der Wasserwellen [The propagation of water waves]. Z. Ver. Dtsch. Ing. 36(33): 947-954
[7] Dressler R F 1952 Hydraulic resistance effect upon the dambreak functions. J. Res. Natl. Bur. Stand. 49(3): 217-225

[8] Su S T and Barnes A H 1970 Geometric and frictional effects on sudden releases. J. Hydraul. Div. 96(11): 2185-2200

[9] Pilotti M, Tomirotti M, Valerio G and Bacchi B 2010 Simplified method for the characterization of the hydrograph following a sudden partial dam break. J. Hydraul. Eng. 136(10): 693-704

[10] Feizi Khankandi A, Tahershamsi A and Soares-Frazão S 2012 Experimental investigation of reservoir geometry effect on dam-break flow. J. Hydraul. Res. 50(4): 376-387

[11] Hooshyaripor F and Tahershamsi A 2015 Effect of reservoir side slopes on dam-break flood waves. Eng. Appl. Comput. Fluid Mech. 9(1): 458-468

[12] Ponce V M 1982 Documented cases of earth dam breaches. In: SDSU Civil Engineering Series. San Diego, CA: San Diego State University

[13] Lauber G and Hager W H 1998 Experiments to dambreak wave: horizontal channel. J. Hydraul. Res. 36(3): 291-307

[14] Taher-shamsi A, Ponce V M and Shetty A V 2003 Embankment dam breaching: geometry and peak outflow characteristics. Dam Eng. 14(2): 73-82

[15] Leal J G A B, Ferreira R M L and Cardoso A H 2009 Maximum level and time to peak of dam-break waves on mobile horizontal bed. J. Hydraul. Eng. 135(11): 995-999

[16] Vischer D L and Hager W H 1998 Dam hydraulics. Chichester: Wiley

[17] SonTec 2007 User guide of Horizon ADV/YSI MicroADV. Available from http://www.sontek.com

[18] Oertel M and Bung D B 2012 Initial stage of two-dimensional dam-break waves: laboratory versus VOF. J. Hydraul. Res. 50(1): 89-97

[19] Escande L, Nougaro J, Castex L and Barthet H 1961 Influence de Quelques Paramètres sur une Onde de Crue Subite à l'Aval d'un Barrage (The influence of certain parameters on a sudden flood wave downstream from a dam). J. Houille Blanche 5: 565-575

[20] Zhao W, Chen X, You Y and Chen J 2015 Dam-break characteristics of landslide dams with different types of open channel discharge sections. Environ. Earth Sci. 74(6): $5331-5340$ 